\title{
TiO2-Cu/Ni nanoparticles for photocatalytic reduction of Aminopyrine
}

\author{
Lei Wang \\ School of Chemical and Environmental Engineering, Shanghai Institute of Technology, Shanghai \\ 201418, China \\ tyrone217@163.com
}

Keywords: aminopyrine; TiO2; Cu/Ni alloy; photocatalysis.

\begin{abstract}
In this work, we take the aminopyrine as the model pollutant in order to explore the $\mathrm{Cu} / \mathrm{Ni}$ ratio effect on the photocatalytic activity of $\mathrm{TiO} 2$ nanoparticles. According to some researches, it is the best method to load of $0.1 \mathrm{~mol} \%$, the $\mathrm{Cu} / \mathrm{Ni}$ ratio $1: 1$, and the photocatalytic activity of $\mathrm{TiO} 2$. Under low concentrations of antibiotics, there will be excellent treatment effects.
\end{abstract}

\section{Introduction}

Aminopyrine is one of the widely used anti-inflammatory analgesic drugs, which focuses on human healthcare and animals breeding ${ }^{[1]}$. However, the rate of human body to the antibiotic drug metabolic is low, and most of the drugs' prototypes will be excreted in the urine and stools ${ }^{[2]}$. In addition, if the antibiotic residues in the environment, it will lead to severe damages to target organs, and do harm to human health, such as having negative impacts on the respiratory function of human body ${ }^{[3]}$.

Recently, the commonly used methods, flocculation, sedimentation, filtration and adsorption of antibiotic wastewater treatment process of amidopyrine drugs are not effective enough, such as removing effect ${ }^{[4]}$. Nevertheless, Photocatalysis is non-toxic, safe, high efficiency and low energy consumption, It made up for the inadequacy of traditional method and plays an important role in the field of antibiotic wastewater treatment ${ }^{[5.6]}$.

In this report, we will use solvent hot method to load $\mathrm{Cu} / \mathrm{Ni}$ on the surface of $\mathrm{TiO}_{2}$. With the model pollutant, we will discuss the $\mathrm{TiO}_{2}$ load of $\mathrm{Cu} / \mathrm{Ni}$ alloy in the application of the photocatalytic degradation of amidopyrine pollutants.

\section{Experiments}

$\mathrm{TiO}_{2}-\mathrm{Cu} / \mathrm{Ni}$ nanoparticles synthetic drugs are used for the analysis of pure. A typical synthesis methods of $\mathrm{TiO}_{2}-\mathrm{Cu} / \mathrm{Ni}{ }^{[7]}$ : First, Weigh $160 \mathrm{mg}$ of P25 and disperse it in $25 \mathrm{ml}$ deionized water. Second, add $0.1 \mathrm{ml} 0.01 \mathrm{~mol} / \mathrm{L} \mathrm{Cu}\left(\mathrm{NO}_{3}\right)_{2}$ solution and $0.1 \mathrm{ml} 0.01 \mathrm{~mol} / \mathrm{L} \mathrm{Ni}\left(\mathrm{NO}_{3}\right)_{2}$ solution in it. Third, after stirring for 1 hour at room temperature, add $0.4 \mathrm{ml} 0.05 \mathrm{~mol} / \mathrm{L}$ hydrazine hydrate solution. Fourth, continue stirring after 10 minus, and use $0.01 \mathrm{~mol} / \mathrm{L} \mathrm{NaOH}$ solution to adjust the above precursor solution $\mathrm{pH}=10$. Sixth, stir again after 10 minutes, and move the precursor solution into 50 $\mathrm{ml}$ in the high-pressure reaction kettle with ptfe lining. Under $150{ }^{\circ} \mathrm{C}$ constant temperature solvent, the solution should be dictated for 3 hours. After reaction, natural cooling to room temperature, and collect the white precipitate. Then centrifugal cleaning with deionized water and ethanol for 3 times. Finally, the obtained solid $45{ }^{\circ} \mathrm{C}$ vacuum dry for 12 hours. By finishing these steps, the $\mathrm{TiO}_{2}$ nanoparticles that load $0.1 \mathrm{~mol} \% \mathrm{Cu} / \mathrm{Ni}$ (1:1) is prepared.

Photocatalytic reaction was carried out in a sealed quartz reactor $(50 \mathrm{~mL})$ at room temperature. Firstly, put a certain concentration of amidopyrine solution into the quartz tube reactor, and add a certain quality of $\mathrm{TiO}_{2}$. Before the illumination, avoid light stiring 40 minus at room temperature. Secondly, use a condensed water jacket of 500W mercury lamp as light source to photocatalytic degradation reactions. Light source and reactor center distance should be $10 \mathrm{~cm}$ with a light filter to remove more than $400 \mathrm{~nm}$ wavelength light. Finally, remove solid catalyst by using $0.25 \mu \mathrm{m}$ membrane filter, and measure it with the UV-vis spectrophotometer. 


\section{Results and Discussion}

\subsection{Characterization of catalysts}

According to Figure 1, there is no obvious change by comparing the samples of the XRD diffraction peak and the diffraction peak of $\mathrm{P}^{2} 5^{[8]}$. It illustrates that the $\mathrm{TiO}_{2}$ crystal structure did not change. The load of metal $\mathrm{Cu}$ and $\mathrm{Ni}$ was not into the lattice of $\mathrm{TiO}_{2}$. However, there is no diffraction peak of $\mathrm{Cu}$ and $\mathrm{Ni}$. In my opinion, it may be the load of $\mathrm{Cu}$ and $\mathrm{Ni}$ is too low, and load on the surface of the metal particle size is too small, which will lead to the ambiguilty.

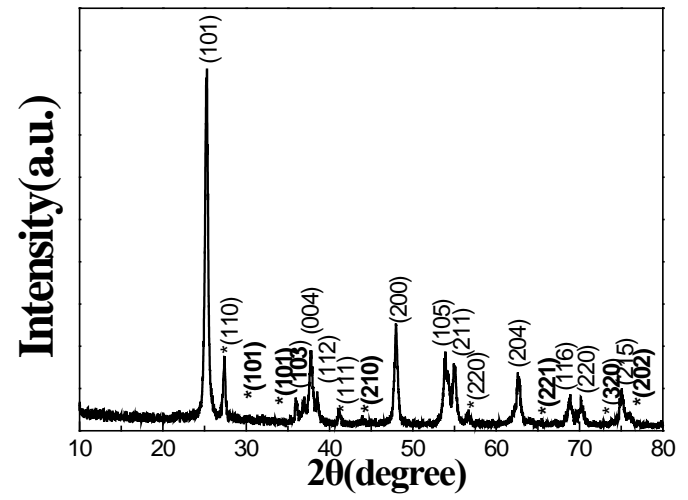

Fig. 1 X-ray diffraction diagram of TiO2-0.1 mol\% Cu/Ni (1:1) nanoparticles

Figure 2 shows the EDX analysis of $\mathrm{TiO}_{2}-0.1 \% \mathrm{Cu} / \mathrm{Ni}$ (1:1). From figure 2, copper, nickel, titanium and oxygen are observed in the sample. Besides, the atomic ratio of $\mathrm{Cu} / \mathrm{Ni}$ is about 1:1. This further indicated that copper and nickel were loaded on surfaces of $\mathrm{TiO}_{2}$ nanoparticles. What's more, from figure 2, $\mathrm{Cu}$ and $\mathrm{Ni}$ loaded on $\mathrm{TiO}_{2}$ nanoparticles are found to be alloy which is in accordance with literature report ${ }^{[7]}$.

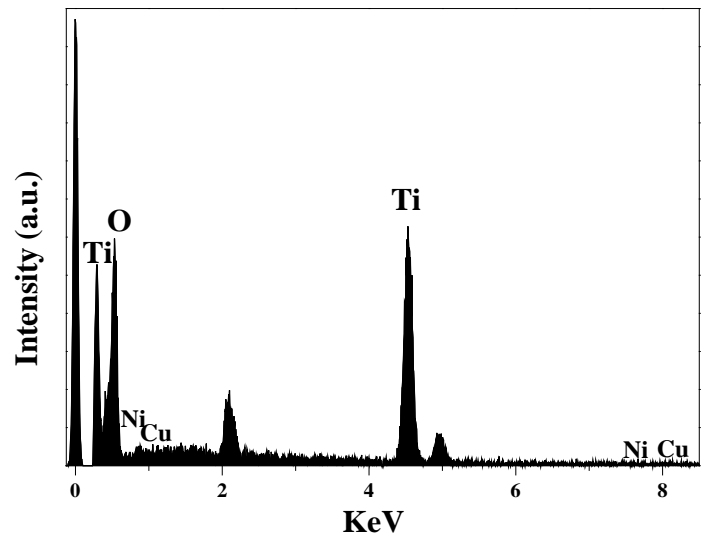

Fig. 2 TiO2-0.1\% Cu/Ni (1:1) EDX analysis element

\subsection{TiO2-Cu/Ni photocatalytic activity}

Figure 3 points the amidopyrine photodegradation kinetics curve on the $\mathrm{TiO}_{2}-0.1 \% \mathrm{Cu} / \mathrm{Ni}(1: 1)$ under UV irradiation. According to figure 3, under the effect of $\mathrm{TiO}_{2}-0.1 \% \mathrm{Cu} / \mathrm{Ni}(1: 1)$ catalyst, amidopyrine between 0 to 4 minus photocatalytic degradation speed is very fast. As the reaction to continue, amidopyrine photocatalytic degradation reaction speed is slow down in some extent. After 12 minus' illumination, photocatalytic reaction basic reaches a balance, at this point, the degradation of amidopyrine rate is about $99 \%$. While the use of pure P25 as a photocatalyst, the degradation of amidopyrine rate is only $60 \%$ under the same condition. Thus, it can be seen that after loading the $\mathrm{Cu} / \mathrm{Ni}$ alloy, the photocatalytic activity of $\mathrm{TiO}_{2}$ nanoparticles is be significantly improved. 


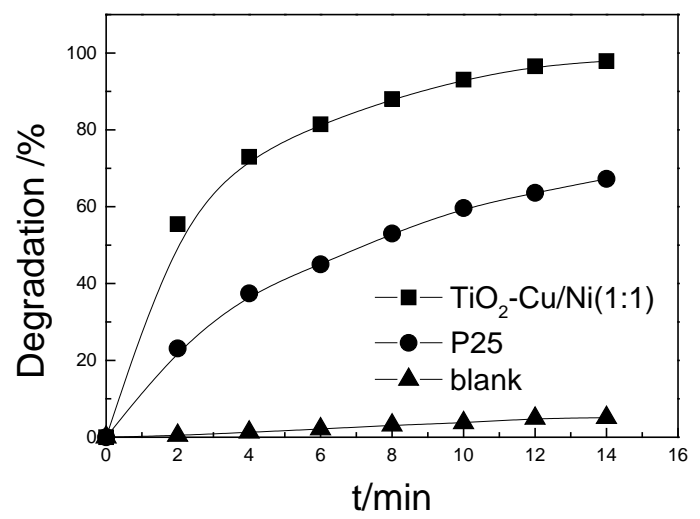

Fig. 3 Amidopyrine photodegradation kinetics curves (Dosage of photocatalysts: $1 \mathrm{~g} / \mathrm{L}$, Amidopyrine concentration $5 \times 10-5 \mathrm{~mol} / \mathrm{L})$

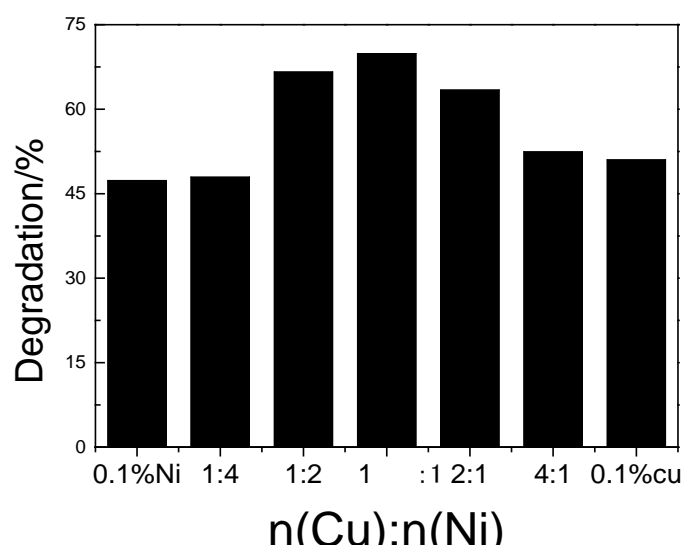

Fig. 4 The proportion of load cocatalyst $\mathrm{Cu}, \mathrm{Ni}$ impact on the photocatalytic activity of $\mathrm{TiO} 2-\mathrm{Cu} / \mathrm{Ni}$, (Dosage of photocatalysts: $1 \mathrm{~g} / \mathrm{L}$, Aminopyrine concentration: $5 \times 10-5 \mathrm{~mol} / \mathrm{L}$, irradiation time: $4 \mathrm{~min}$ )

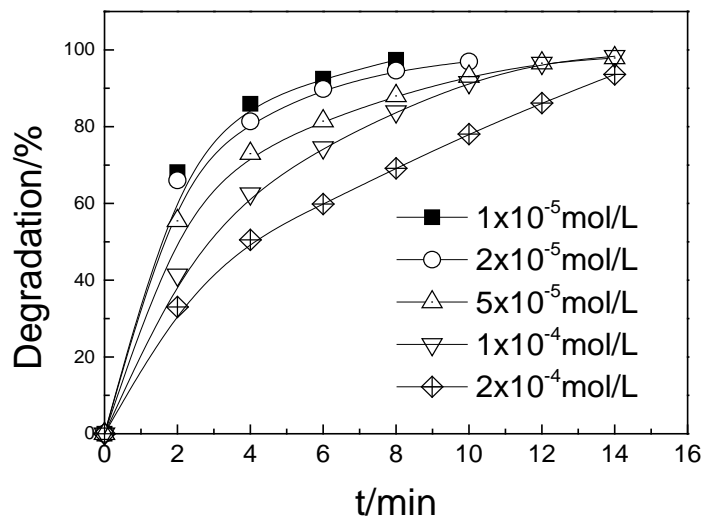

Fig. 5 Amidopyrine the influence of initial concentration of photocatalytic degradation efficiency (Dosage of photocatalysts: $1 \mathrm{~g} / \mathrm{L}$ )

\subsection{The influence of $\mathrm{Cu} / \mathrm{Ni}$ mole ratio}

Figure 4 shows the proportion of load cocatalyst $\mathrm{Cu}, \mathrm{Ni}$ impact on the photocatalytic activity of $\mathrm{TiO}_{2}-\mathrm{Cu} / \mathrm{Ni}$. Experimental results show that after the introduction of $\mathrm{Cu} / \mathrm{Ni}$ alloy, the photocatalytic activity of $\mathrm{t} \mathrm{TiO}_{2}$ has been significantly improved. In addition, the effects of its catalytic activity is better than single load $\mathrm{Cu}$, Ni's. Moreover, $\mathrm{Cu} / \mathrm{Ni}$ mole ratio is $1: 1, \mathrm{TiO}_{2}-\mathrm{Cu} / \mathrm{Ni}$ has the highest photocatalytic activity. It is detrimental to enhance the photocatalytic activity of $\mathrm{TiO}_{2}$ nanoparticles, if the $\mathrm{Cu} / \mathrm{Ni}$ mole ratio is too high or too low. The main reason is when the $\mathrm{Cu} / \mathrm{Ni}$ mole ratio of $1: 1$, the schottky barrier of the height is advantageous for the separation of the electronic-hole between the metal and titanium dioxide produced ${ }^{[9]}$. 


\subsection{The influence of the initial concentration of the amidopyrine}

The concentration of the antibiotics generally is low in the water, and the treatment on low concentration wastewater is a technical difficulty. The traditional treatment methods have few influences on it. The Fig 5 have shown that above, $\mathrm{TiO}_{2}-\mathrm{Cu} / \mathrm{Ni}$ for low concentration of antibiotic wastewater has an efficient treatment impacts. Owing to this, we believe that it has a great application potential for treatment the trace antibiotics pollution from water in the future.

\section{Summary}

Antibiotics is very stable in the water, residual antibiotics in the environment do great harm to ecological environment and human health. Using $\mathrm{TiO}_{2}-\mathrm{Cu} / \mathrm{Ni}$ photocatalytic oxidation to removal the antibiotic pollutant from water has been reached to good effect. Its preparation method has some characteristics, such as simple, cheap material, and high catalytic activity. However, in the aspect of catalyst recycling and the high concentration, wastewater's treatment remains to be improved. Therefore, it is likely to build a new pollution treatment method by combining with other technologies.

\section{References}

[1]. Dai G, Huang J, Chen W, et al. Major pharmaceuticals and personal care products (PPCPs) in wastewater treatment plant and receiving water in Beijing. China, and associated ecological risks. B. Environ. Contam. Tox. 2014 92(6):655-661.

[2]. Haque MM, Muneer. Photodegradation of norfloxacin in aqueous suspensions of titanium dioxide. J. Hazard. Mater. 2007145(1-2):51-57.

[3]. Zühlke S, Dünnbier U, Heberer T. Detection and identification of phenazone-type drugs and their microbial metabolites in ground and drinking water applying solid-phase extraction and gas chromatography with mass spectrometric detection. J. Chromatogr. A. 2004. 1050(2): 201-209.

[4]. Tay KS, Rahman NA. Kinetic studies of the degradation of parabens in aqueous solution by ozone oxidation. Environ. Chem. Lett. 2009. 8(4), 331-337.

[5]. Miranda N, Maldonado MI,Coronado JM, et al. Degradation study of 15 emerging contaminants at low concentration by immobilized TiO2 in a pilot plant. Catalysis Today 2010 151(1-2): 107-113.

[6]. Peter A, Mihaly-Cozmuta L, Mihaly-Cozmuta A, et al. Efficiency of $\mathrm{Cu} / \mathrm{TiO} 2$ to remove salicylic acid by photocatalytic decomposition: kinetic modelling. Mater. Technol. 2014.29(3):129-133.

[7]. Tian H, Kang SZ, Li X, Qin L,et al. Fabrication of an efficient noble metal-free TiO2-based photocatalytic system using $\mathrm{Cu}-\mathrm{Ni}$ bimetallic deposit as an active center of $\mathrm{H} 2$ evolution from water. Sol. Energ. Mater. Sol. C., 2015, 134, 309-317.

[8]. Janus M, Morawski AW. New method of improving photocatalytic activity of commercial Degussa P25 for azo dyes decomposition. Appl. Catal. B- Environ. 2007. 75(1-2), 118-123.

[9]. Riaza N, Chong FK, Duttac-Binay K, et al. Photodegradation of Orange II under visible light using Cu-Ni/TiO2: Effect of calcination temperature. Chem. Eng. J. 2012. 185(186):108-119. 